\title{
PENDAMPINGAN EDUKASI GIZI DAN KESEHATAN REPRODUKSI PADA GURU DI WILAYAH GUGUS SERUNI PEDURUNGAN SEMARANG
}

\section{ACCOMPANIMENT OF NUTRITION DAN EARLY REPRODUCTION HEALTH EDUCATION IN SERUNI COMMUNITY TEACHER PEDURUNGAN SEMARANG}

\author{
Vilda Ana Veria Setyawati ${ }^{\left.1^{*}\right)}$, Eti Rimawati ${ }^{2)}$ \\ ${ }^{1,2}$ Kesehatan Masyarakat, Universitas Dian Nuswantoro \\ ${ }^{1}$ Email: vilda.setyawati@dsn.dinus.ac.id
}

\begin{abstract}
Abstrak : Program kemitraan masyarakat dilaksanakan di KB TK Binarrahman dengan peserta guru-guru KB dan TK yang tergabung di Gugus Seruni UPTD Pedurungan selama bulan Desember 2019 dan Januari 2020 dengan total peserta yang aktif berjumlah 18 guru. Tujuan kegiatan ini untuk mengatasi permasalahan yang dihadapi mitra yaitu, guru belum mendapat pelatihan gizi dan kesehatan reproduksi, kurangnya sarana edukasi kedua hal tersebut, dan sekolah tidak memiliki alat antropometri gizi yang sesuai standar. Tahapan kegiatan meliputi pelatihan kepada guru-guru selama sehari penuh yang diawali dan diakhiri dengan pre dan post test. Materi gizi yang diberikan meliputi gizi seimbang pada balita, stunting, dan antropometri. Materi kesehatan reproduksi dini yang diberikan meliputi pengenalan organ tubuh, bagaimana cara membersihkan dan melindunginya. Setelah itu 1 bulan kemudian, dilakukan monitoring dan evaluasi pelaksanaan edukasi gizi seimbang dan kesehatan reproduksi usia dini dari guru ke siswa. Hasil uji beda pengetahuan pre dan post test menunjukkan adanya perbedaan yang signifikan dari keduanya (uji wilcoxon) yang didukung dengan analisis frekuensi dimana, pada saat post test, yang mendapatkan nilai baik meningkat dari $44,4 \%$ menjadi $72,2 \%$.
\end{abstract}

Kata Kunci: PAUD-HI, guru, siswa, gizi, kesehatan reproduksi.

Abstract: The community partnership program was carried out at KB TK Binarrahman. The participant consist of teacher who teach at seruni community, Pedurungan Cluster during December 2019 and January 2020 with a total of 18 active participants. The purpose of this activity is to overcome the problems faced by partners. There were teachers have not received training in nutrition and reproductive health, lack of educational facilities both of these, and schools do not have appropriate anthropometric nutrition tools. Stages of activities include training for teachers for a full day which begins and ends with pre and post test. Nutrition materials provided include balanced nutrition in infants, stunting, and anthropometry. Early reproductive health material provided includes the introduction of body organs, how to clean and protect them. After that, 1 month later, monitoring and evaluating the implementation of balanced nutrition education and early reproductive health from teacher to student. The results of the different pre and post test knowledge tests showed a significant difference between the two (wilcoxon test), which was supported by frequency analysis which, at the time of the post test, which gained good scores increased from $44.4 \%$ to $72.2 \%$.

Keyword: PAUD-HI, teachers, students, nutrition, health reproduction. 


\section{INTEGRITAS : Jurnal Pengabdian}

Vol 4, No 1, Juli 2020

ISSN 2580-7978 (cetak) ISSN 2615-0794 (online)

\section{PENDAHULUAN}

Program PAUD Holistik-Integratif (PAUD-HI) disahkan untuk dilaksanakan di seluruh PAUD berdasarkan Peraturan Presiden Republik Indonesia No. 60 tahun 2013. Secara umum tujuannya agar siswa PAUD memperoleh stimulasi pertumbuhan dan perkembangan yang berkualitas demi pencapaian tahap kehidupan selanjutnya. Keberadaan PAUD-HI dapat memenuhi kebutuhan esensial anak secara simultan, sistematis, dan terintegrasi melalui layanan stimulasi holistik yang mencakup pendidikan, kesehatan, gizi, perawatan, pengasuhan, dan perlindungan anak dalam satu tempat tersebut (Kemdikbud, 2015).

Semarang memiliki 812 TK dan lebih dari 400 PAUD yang tersebar di seluruh kelurahannya. Gugus seruni merupakan kumpulan dari sekolah KB dan TK di wilayah UPTD Kecamatan Pedurungan. Gugus ini terdiri dari sekitar 8 sekolah dengan jumlah guru sekitar 20. Sekolah yang ada di gugus ini, belum semuanya terakreditasi dengan kendala beragam. Akan tetapi, mulai tahun ajaran 2020 diharapkan oleh UPTD PAUD Pedurungan, sudah siap melaksanakan PAUD-HI pada siswa siswinya. Apabila dilihat dari aspek layanan yang disyaratkan untuk hal tersebut, mereka diprediksi sudah dapat dilaksanakan. Akan tetapi sekolah ini memiliki kekurangan di bidang gizi dan kesehatan. Para guru belum pernah mendapatkan pelatihan PAUD-HI dan juga belum mendapat pelatihan tentang bagaimana penerapan edukasi gizi dan kesehatan pada anak didiknya. Selain itu, mereka belum memiliki alat edukasi yang sesuai untuk kedua hal tersebut.

Penelitian yang dilakukan di PAUD HI di RA YPIRA Kota Bandung menunjukkan bahwa program pembelajaran yang mencakup layanan yang disyaratkan oleh PAUD HI telah berjalan dengan baik yang dilihat dari indikator yang berhasil dipenuhi yaitu meningkatnya perkembangan dan pencapaian pertumbuhan anak sesuai dengan tahapan usianya. Untuk mencapainya perlu pendukung antara lain sarana dan prasarana yang memadai, pendidik yang kompeten dan adanya dukungan anggaran. Pemahaman pendidikan tentang 
INTEGRITAS : Jurnal Pengabdian

Vol 4, No 1, Juli 2020

ISSN $2580-7978$ (cetak) ISSN 2615 - 0794 (online)

layanan yang harus dipenuhi oleh pendidik akan menghambat pencapaian indikator keberhasilan PAUD HI (Pendidikan, Litbang and Agama, 2017). Evaluasi pelaksanaan PAUD HI di Mamuju menunjukkan perlunya meningkatkan kompetensi tenaga kependidikan untuk mengikuti pelatihan yang dapat mendukung terselenggaranya layanan yang termasuk dalam cakupan PAUD HI (Hajati, 2018).

Berdasarkan uraian di atas, permasalahan yang ditemukan dilokasi mitra yaitu :

1. Guru belum mendapat pelatihan gizi dan kesehatan reproduksi

2. Kurangnya sarana edukasi kedua hal tersebut

3. Sekolah tidak memiliki alat antropometri gizi yang sesuai

Perlu solusi yang segera dilaksanakan untuk mengatasi permasalahan dia atas untuk mempercepat kesiapan guru dan KB TK di Gugus Seruni dalam penyelenggaraan PAUD-HI.

\section{METODE PELAKSANAAN}

Program kemitraan masyarakat dilaksanakan di KB TK Binarrahman dengan peserta guru-guru KB dan TK yang tergabung di Gugus Seruni UPTD Pedurungan selama bulan Desember 2019 dan Januari 2020 dengan total peserta yang aktif berjumlah 18 guru. Solusi yang ditawarkan untuk mengatasi masalah tersebut meliputi pelatihan yang berfokus pada layanan gizi seimbang dan kesehatan reproduksi dini untuk balita. Tahapan kegiatan meliputi pelatihan kepada guru-guru selama sehari penuh yang diawali dan diakhiri dengan pre dan post test. Materi gizi yang diberikan meliputi gizi seimbang pada balita, stunting, dan antropometri. Materi kesehatan reproduksi dini yang diberikan meliputi pengenalan organ tubuh, bagaimana cara membersihkan dan melindunginya. Setelah itu 2 minggu kemudian, dilakukan monitoring dan evaluasi pelaksanaan edukasi gizi seimbang dan kesehatan reproduksi usia dini dari guru ke siswa. Untuk mengetahui efektifitas pelatihan, peserta diminta menjawab soal pre dan 


\section{INTEGRITAS : Jurnal Pengabdian}

Vol 4, No 1, Juli 2020

ISSN 2580-7978 (cetak) ISSN 2615-0794 (online)

post test. Nilai keduanya diuji beda dengan menggunakan uji wilcoxon dengan tingkat kesalahan $10 \%$.

\section{HASIL DAN PEMBAHASAN}

Kegiatan diawali dengan sosialisasi dan koordinasi jadwal pelaksanaan kegiatan secra menyeluruh kepada para tenaga pendidik di KB TK Binarrahman. Hasil dari koordinasi tersebut, disepakati jadwal sebagai berikut :

Tabel 1. Rencana kegiatan pengabdian

\begin{tabular}{lll|l|l|l|l|l|l|l}
\hline \multirow{2}{*}{ No } & \multirow{2}{*}{ Nama Kegiatan } & \multicolumn{7}{c}{ Desember 2019} & \multicolumn{7}{c}{ Januari 2020 } \\
\cline { 2 - 9 } & & 1 & 2 & 3 & 4 & 1 & 2 & 3 & 4 \\
\hline 1 & Sosialisasi dan persiapan & & & & & & & & \\
2 & Pelatihan gizi dan reproduksi & & & & & & & & \\
3 & Monitoring dan Evaluasi & & & & & & & & \\
\hline
\end{tabular}

Secara umum pelaksanaan kegiatan yang dijelaskan pada metode direalisasikan dalam 2 tahap yaitu pelatihan dan monitoring evaluasi. Pelatihan dilakukan pada bulan Desember 2019 dengan rincian kegiatan sebagai berikut :

\section{Pelatihan gizi seimbang}

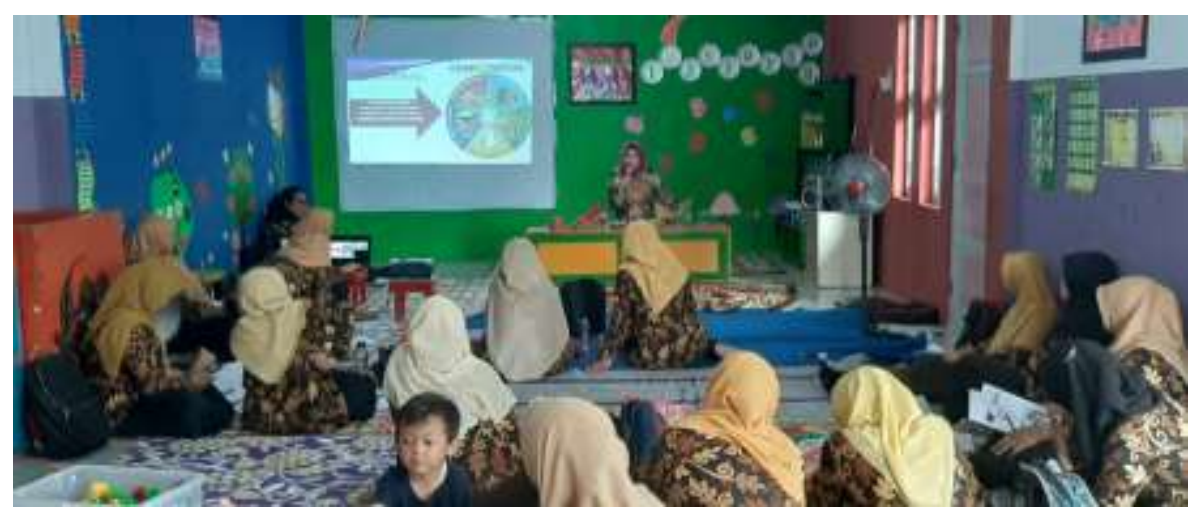

Gambar 1. Materi gizi seimbang

Pemahaman sebagian besar masyarakat Indonesia tentang gizi seimbang masih seputar empat sehat lima sempurna. Padahal konsep gizi seimbang sudah diganti sejak tahun 2014 dan divisualisasikan dalam bentuk gambar piring makanKu dan tumpeng gizi. Hal ini dinilai lebih efektif untuk memperbaiki gizi anak bangsa dibandingkan konsep sebelumnya. Saat anak memasuki usia 3 tahun ke atas, biasanya orang tua mereka sudah mulai memasukkannya ke sekolah PAUD. Bekal 
menjadi bawaan wajib yang disediakan orang tua untuk dimakan bersama temanteman di sekolah. Peran guru disekolah adalah memantau agar siswanya mengkonsumsi bekal tersebut dan memastikan asupan gizinya dari bekalnya sesuai dengan prinsip gizi seimbang. Sebelum acara dilaksanakan, diskusi gizi seimbang dibahas dan semua guzu di lokasi mitra masih menganggap bahwa gizi seimbang adalah empat sehat lima sempurna. Sehingga penting untuk mengubah pandangan guru tentang gizi seimbang melalui kegiatan-kegiatan seperti ini.

\section{Pelatihan kesehatan reproduksi usia dini}

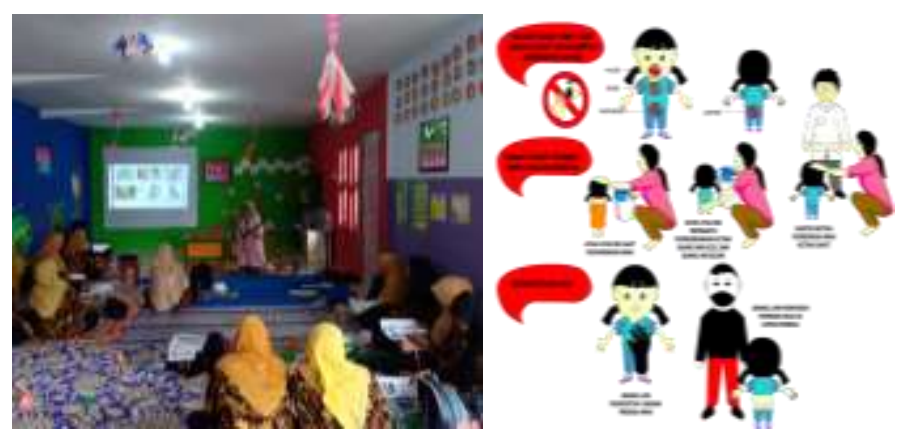

Gambar 2. Materi Gizi Seimbang

Kesehatan dasar untuk anak-anak dalam hal ini juga penting untuk dipahami oleh guru. Sejauh ini layanan kesehatan yang ada baru sebatas mencuci tangan sebelum makan atau setelah bermain. Tetapi diskusi awalpun juga menunjukkan bahwa guru masih belum memahami pentingnya kesehatan reproduksi dasar. Anak perlu mengenal dan melindungi bagian-bagian tubuhnya. Serta siapa saja yang boleh menyentuhnya pada saat kondisi tertentu. Hal ini perlu dipahami mengingat banyaknya pelaku kejahatan seksual dengan sasaran anak-anak berasal dari orang terdekatnya.

\section{Indikator nilai pengetahuan}

Tabel 2. Deskripsi nilai peserta sebelum dan setelah mendapatkan pelatihan

\begin{tabular}{lrrrrr}
\hline Variabel & Jumlah & Nilai terendah & Nilai tertinggi & Rata-rata & Wilcoxon test \\
\hline Pre test & 18 & 9 & 15 & 12.06 & $\mathrm{p}=0,081$ \\
Post test & 18 & 9 & 15 & 12.94 & \\
\hline
\end{tabular}




\section{INTEGRITAS : Jurnal Pengabdian}

Tabel 2 menunjukkan bahwa seluruh peserta mengerjakan soal pre test dan post test. Jika dilihat reratanya, tidak begitu banyak perbedaan selisih. Akan tetapi uji beda menunjukkan adanya perbedaan yang signifikan dari keduanya dengan tingkat kesalahan 0,1. Hasil ini didukung dengan hasil analisis frekuensi dimana, pada saat post test, yang mendapatkan nilai baik meningkat dari $44,4 \%$ menjadi $72,2 \%$. (gambar 3$)$
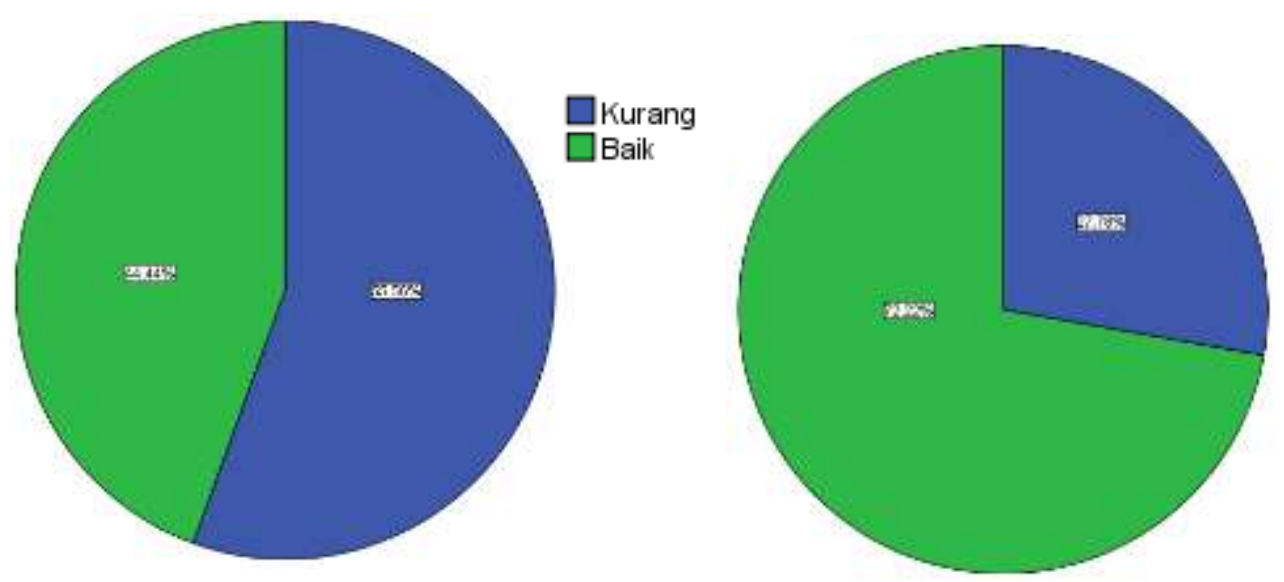

Gambar 3. Hasil pre dan post test

\section{Monitoring dan Evaluasi pada KB TK Binarrahman}

Untuk mengetahui apakah guru menguasai materi pelatihan, tidak cukup jika hanya dilihat dari hasil pre dan post test saja. Akan tetapi perlu dilihat bagaimana mereka melakukannya secara langsung. Kegiatan tersebut dilakukan secara simbolis pada 1 sekolah yaitu KB TK Binarrahman, meliputi sebagai berikut : 


\section{INTEGRITAS : Jurnal Pengabdian}

Vol 4, No 1, Juli 2020

ISSN $2580-7978$ (cetak) ISSN 2615 - 0794 (online)

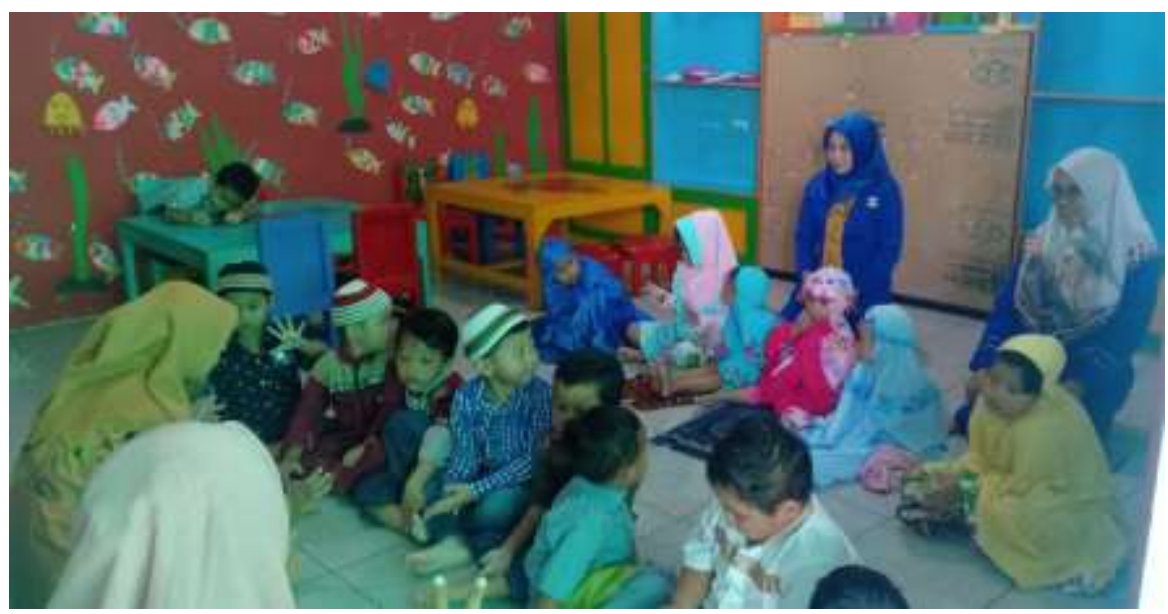

Gambar 4. Praktek edukasi gizi dan kesehatan reproduksi usia dini dari guru ke siswa

Guru dapat mengajarkan kepada siswa bagaimana cara melindungi bagian tubuh secara sederhana dengan menggunakan media gambar. Kelemahan pembelajaran pada anak-anak adalah kebosanan jika guru sering memberikan hal yang sama berulang kali, sehingga disepakati, edukasi tersebut tidak dilakukan setiap hari melainkan seminggu sekali.

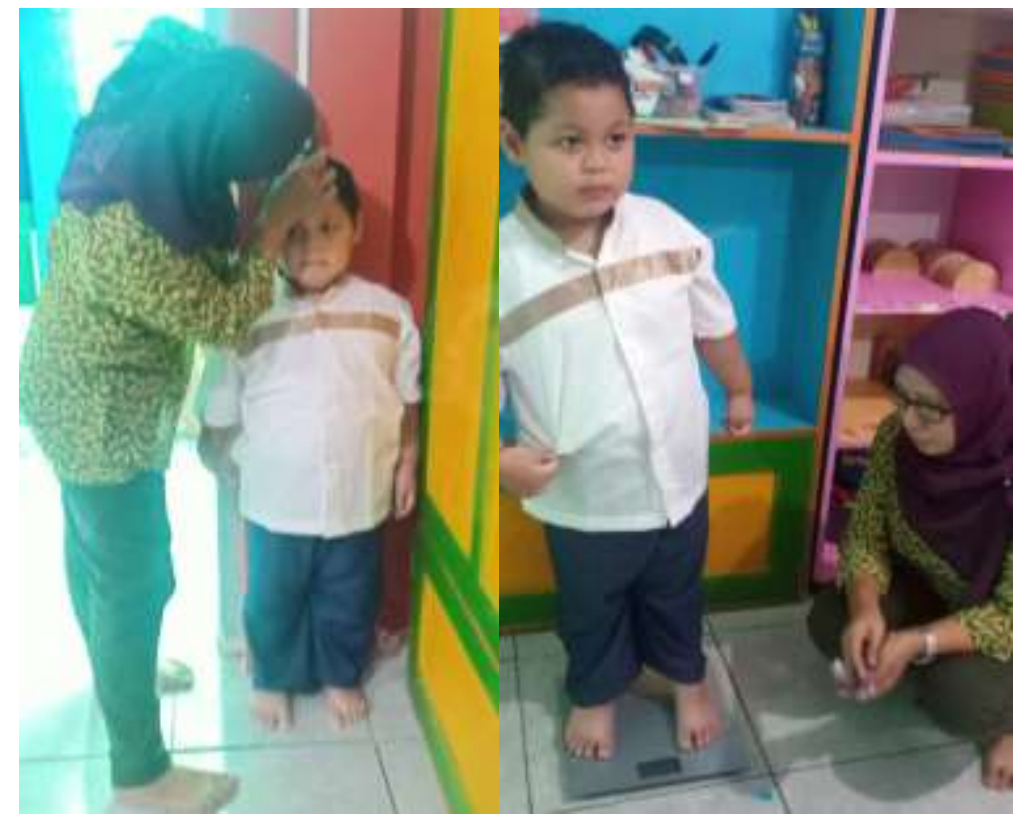

Gambar 5. Praktek menimbang berat badan dan mengukur tinggi badan 


\section{INTEGRITAS : Jurnal Pengabdian}

Selain itu, guru juga diminta untuk melakukan praktek langsung bagaimana cara menimbang menggunakan timbangan digital dan mengukur tinggi badan dengan mikrotoa. Sebelumnya, anak diukur antropometri dengan berdiri semaunya. Hal ini dapat membuat hasil pengukuran menjadi bias. Sehingga setelah kegiatan ini, guru dapat melakukan pengukuran dengan tepat.

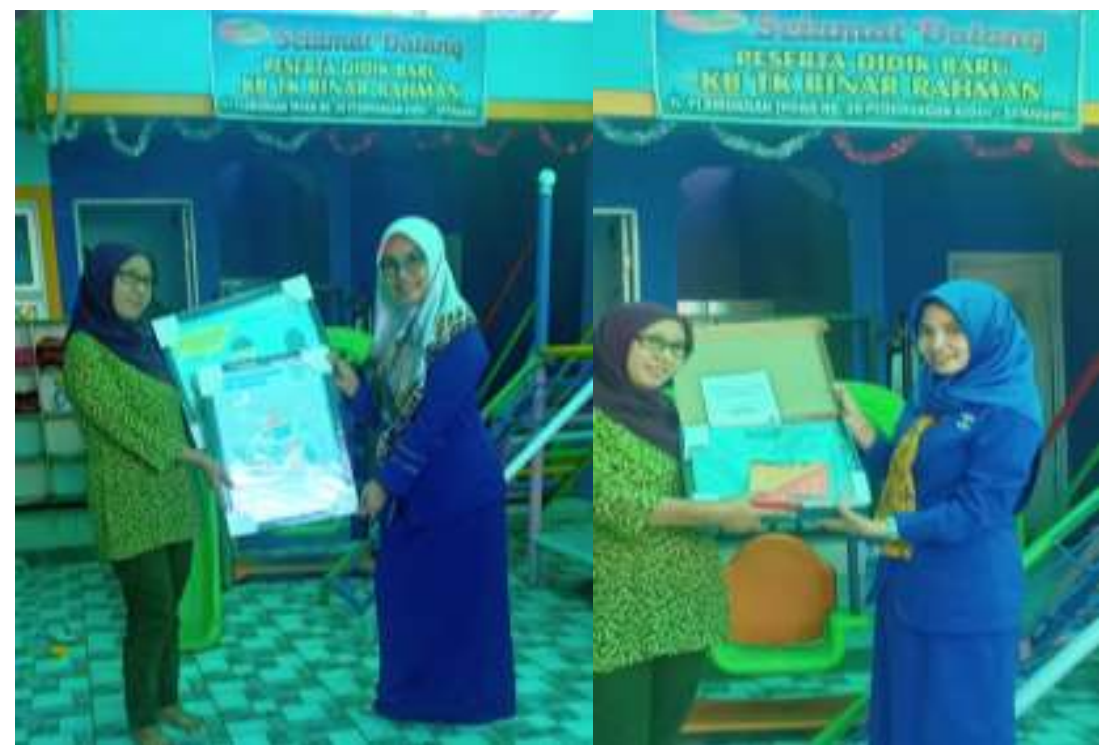

Gambar 6. Penyerahan poster edukasi dan alat antropometri gizi

Seluruh acara diakhiri dengan penyerahan poster edukasi gizi seimbang dan kesehatan reproduksi dini yang sudah diuji pada siswa secara sederhana dan dianggap dapat dipamahi. Selain itu juga diberikan timbangan digital dan mikrotoa untuk dipakai pengukuran antropometri setiap bulan. Peningkatan kemampuan dan keterampilan guru sesuai kompetensi pengajaran sangat penting. Ada tiga hal utama yang didapat yaitu peningkatan kualitas pembelajaran dengan sarana dan prasarana yang ada, peningkatan kemampuan membuat pajangan dan APE di kelas, dan peningkatan pengelolaan manajemen PAUD (Aulina, Rezania and Destiana, 2018). 
INTEGRITAS : Jurnal Pengabdian

Vol 4, No 1, Juli 2020

ISSN $2580-7978$ (cetak) ISSN 2615 - 0794 (online)

\section{KESIMPULAN}

Permasalahan yang ditemukan dilapangan dapat diatasi dengan adanya kegiatan pengabdian ini. Guru mengikuti pelatihan gizi dan kesehatan reproduksi dini dengan baik yang dilihat dari rerata kenaikan nilai sebelum dan sesudah pelatihan. Efektivitasnya juga didukung dari hasil monitoring dan evaluasi pada salah satu skeolah, dimana guru dapat melakukan kompetensi yang diharapkan sesuai target.

\section{UCAPAN TERIMA KASIH}

Kami mengucapkan terima kasih kepada Universitas Dian Nuswantoro yang telah memberikan dana melalui Lembaga Penelitian dan Pengabdian kepada Masyarakat melalui skim Program Kemitraan Masyarakat periode semester gasal 2019/2020.

\section{DAFTAR PUSTAKA}

Aulina, C. N., Rezania, V. and Destiana, E. (2018) "Pengabdian Kepada Masyarakat Melalui Pendampingan Bagi Guru Pos Paud," Jurnal ABDI, 3(2), p. 41. doi: 10.26740/ja.v3n2.p41-45.

Hajati, K. (2018) "Pelaksanaan Pendidikan Holistik-Integratif dalam Pelayanan Kebutuhan Dasar Anak Usia Dini di Kabupaten Mamuju Sulawesi-Barat," Indonesian Journal of Educational Science (IJES), 1(1), pp. 17-24. doi: 10.31605/ijes.v1i1.133.

Kemdikbud (2015) Petunjuk Teknis Penyelenggaraan PAUD Holistik Integratif di Satuan PAUD.

Pendidikan, P., Litbang, B. and Agama, K. (2017) "PENDIDIKAN HOLISTIK INTEGRATIF DI RAUDLATUL ATHFAL ( RA ) INTEGRATIVE HOLISTIC EDUCATION AT RAUDLATUL ATHFAL ( RA ),” 15(2), pp. 241-262. 